\title{
The Relationship Between Premarital Expectation and Marital Satisfaction Among Married Couples in Bole Sub-city of Addis Ababa City Administration
}

\author{
Girma Deressu \\ Addis Ababa University, Addis Ababa, Ethiopia \\ Zewdu Girma \\ Madda Walabu University, Bale Robe, Ethiopia
}

\begin{abstract}
The aim of this study was to investigate the relationship between married couples' premarital expectations and marital satisfaction in the Bole sub-city of Addis Ababa. A quantitative descriptive survey was employed in this study. A sample of 100 married couples (200 participants) was used as a primary source of data. The sampling technique employed was a convenience sampling method. A self-administered questionnaire was used to collect data from primary sources. Pearson's correlation, standard linear regression, one way ANOVA, and independent T-test were used as data analysis techniques with an acceptable significance level $(\mathrm{p}<0.05)$. The result of the study indicated that there was a significantly positive relationship between premarital expectation and marital satisfaction. Marital communication was observed to have a statistically significant predictor effect on marital satisfaction. Socio-demographic factors assumed to have a contribution to variance in premarital expectations and marital satisfaction of couples have been identified; educational level, religious affiliation, and source of marital information were identified to have a contribution to differences in premarital expectation. Age, religious affiliation, income level, and duration of courtship were identified to have a significant contribution to differences in marital satisfaction of married couples. The findings of the study have practical implications in marriage counseling, couples capacity building training, couples conflict resolution, and for researchers in the area of marriage and marital relationship.
\end{abstract}

Keywords: premarital expectation, marital satisfaction, relationship, couple

\section{Introduction}

It is indiscriminately human to have the intention and desire to set up a family and lead a satisfying married life. It is also normal to perceive and expect to realize what we would like to achieve. Premarital expectations are all about what we expect to happen in our married life. It is a desire that needs to be met by someone else, and thus its realization is largely out of their control. When we expect something to occur, it's no big deal when it happens. But it can be incredibly disappointing or frustrating when it does not. Because of this,

Girma Deressu, MA in Counseling Psychology, Lecturer, Department of Psychology, Addis Ababa University, Addis Ababa, Ethiopia.

Zewdu Girma, MA in Counseling Psychology, Lecturer, Department of Psychology, Madda Walabu University, Bale Robe, Ethiopia. 
having expectations in the long term relationship can be a problem whether they are met or not. If expectations are not met, it's going to cause us to feel negative about our partner and possibly even treat them poorly. If our expectations are met, it will not cause us to offer praise, which can lead to our significant other feeling unappreciated and not meeting our expectations in the future.

Marital satisfaction means a good feeling of marriage. Kaplan and Maddux (2002) stated that marital satisfaction is an individual experience in marriage, which can only be evaluated by each person in response to the degree of marital pleasure. They believe that it depends upon the individual's expectations, needs, and desires in their marriage. Marital satisfaction refers to the degree of satisfaction between couples. This would mean the degree of satisfaction they feel with their relationship. This satisfaction could be addressed both from the perspective of the wife toward the husband or the husband toward the wife. Marital satisfaction is a special case of relationship satisfaction, and it is the degree to which partners in marriage assess their approval of different aspects of their marital relations. It combines different areas such as effective communication; the amount of time spent together, disagreement on children's management among significant other likely aspects.

Given these normative issues about the relationship between marital expectations and marital satisfaction, earlier studies have shown that marital satisfaction is not so easily achieved (Brassard, Shaver, \& Lussier, 2007) because a wide range of psychological and socio-demographic factors that could affect husband's and wife's behavior, thinking, feelings, communication, and other interpersonal interactions in marriage needed to be taken into account when assessing satisfaction in marriage.

Despite socio-demographical correlates of marital satisfaction, various psychological factors are important for understanding the satisfaction of couples' marital satisfaction is significantly related to the communication peculiarities in a dyad. In addition, beliefs and religious practices have also been shown to give a long-term perspective as well as meaning to marriage (Lambert \& Dollahite, 2008; Weigel, Bennett, \& Bollard-Reisch, 2006).

It has also been found that couples who court longer have a longer time to negotiate roles and expectations and gather information; therefore they enter their marital relationship with less stress and discord (Knoblock \& Donovan-Kicken, 2006). Jose and Alfons (2007) reported that couples with higher education have more stressors within their marriage that affect their marital satisfaction, as well as whom they choose to marry. Researchers have found expectations to be important in their studies because of the large discrepancy between what many America see as the ideal marriage and what actually takes place (Bonds-Raacke, Bearden, Carrier, Anderson, \& Nicks, 2001). Larson and Holman (1994) said that expectations affected marital interactions and satisfaction. In other words, individuals take information or advice and construe their own expectations that are used to evaluate their satisfaction in own marital relationship.

Expectations towards marriage have been found to be a large predictor of marital satisfaction. Expectation includes many things such as intents, attitudes about values and beliefs, as well as gender roles. Having similar or complementary views on each of these things is said to have a positive effect on marital quality and stability (Larson \& Holman, 1994). Studies have been done on marital satisfaction, which affects marital satisfaction and marital expectations. Contemporary married couples are faced with many challenges that require the renegotiation of previously taken-for-granted marital roles and expectations in order to achieve a more intimate, companionable, and committed marriage (Baker, Kiger, \& Riley, 1996).

Moves toward more gender equality have impacted on marital expectations. Both men and women enter marriage with a higher expectation of interpersonal communication, intimacy, and sexual satisfaction. If 
expectations of marriage have increased then one can assume that a more satisfying marriage is the ultimate goal to be achieved by these increased expectations. Given the widespread societal concerns about the high divorce rate, it is important to understand factors that may contribute to marital satisfaction in order to develop interventions that would benefit couples, who are suffering from marital distress, who are considering divorce (Bradbury, Fincham, \& Beach, 2000), or who simply want their personal relationship needs to be fulfilled.

Marital satisfaction is a complex process that has over time been thought to be influenced by many factors, including education, socio-economic status, love, commitment, marital communication, conflict, gender, length of the marriage, the presence of children, sexual relations, and the division of labor (Hendrick \& Hedrick, 1992). Marital satisfaction has for many become a yardstick to measure the success and stability of marriage and by extension, personal fulfillment, and well-being. Although there are contextual variations among different continents and countries, there is an increasing rate of marriage breakdown at the global level.

Daniel Tadesse (2013) reported that the rate of divorce in Ethiopia is highly increased. In Addis Ababa alone, within a year (from January 9, 2005, to January 8, 2006), 6,023 couples were married and of these 1,105 couples were divorced. According to the latest data obtained from the Addis Ababa City Administration Vital Events and Residents Service Agency, the record of divorce in Addis Ababa over the last six years (2002-2007 National Calendars) shows that the divorce recorded over the base year (2002) was 232 and record over last year (2007) has grown to 1,846 . The difference in divorce records between the base year and the last year is 1,614 . These figures show that the divorce rate is increasing by $323(139 \%)$ per year.

Apart from the highly increasing rate of divorce, the invisible consequences of family breakdown on individual family members, particularly young children are tragic. The researcher had observed and worked with young adolescents whose parents have divorced at their childhood age and have been living with extended family members for years and reported to have faced multiple challenges that made them vulnerable to all forms of abuse; physical and psychological. Many married couples would say they expect companionship, intimacy, and sharing of feelings. The most successful marriage starts with a solid foundation. That foundation is built on many things - mutual interest, shared beliefs, selflessness, and of course love - but the biggest problem going into many marriages is that those basics are often held back by unrealistic expectations.

All of us know someone for whom marriage did not work out. We have all heard the statistics. First marriages have a failure rate of more than $40 \%$. Second marriages end in divorce $60 \%$ of the time. However, there may be differences in place and time; marriage breakdown is increasing in the western countries, in Africa and also in Addis Ababa as a showcase for the situation in Ethiopia. Although earlier studies have examined supportive factors contributing to satisfying and stable marriage as well as risk factors contributing to marriage breakdown, the relationship between premarital expectations and marital satisfaction seems to have been not well examined in a cross-cultural context. Study reports in the western countries or elsewhere were culture-specific and not viable to generalize them as a universal fact.

However, factors contributing to making or breaking marriage in Ethiopia may have some commonalities with situations in other cultures, the differences in the social and cultural system, beliefs, and values, and socio-demographic factors influencing premarital expectations and marital satisfaction remains unique and the subject of investigation.

Therefore, the present study focused on examining the relationship between premarital expectations, marital communication, and marital satisfaction of married couples, and contributing socio-demographic factors to premarital expectations and marital satisfaction in the Bole sub-city of Addis Ababa. 


\section{Research Questions}

1. Is there a significant relationship between premarital expectations, marital communication, and marital satisfaction of married couples?

2. Do premarital expectation and marital communication predict couples' marital satisfaction?

3. What are the socio-demographic factors (gender, age, education level, religion, income, source of information about marriage, durations of courtship and married life) that contribute to changes in premarital expectation and marital satisfaction?

\section{Research Methodology}

\section{Research Design}

As the study aimed at examining the relationship between premarital expectation and marital satisfaction of married couples, a descriptive survey design was considered as appropriate in view of the objectives and basic questions of the study. A descriptive study is said to "provide information about the physical, social, economic, or psychological characteristics of some group of people" (Leary, 2001, p. 228-237).

Married couples residing in the Bole sub-city of Addis Ababa were used as target population and primary sources of data, and related literature was used as secondary data sources. However, descriptive survey design allows the use of mixed method; a quantitative method was only used entirely in this study due to circumstances that made access to participants a bit difficult and other constraints that limited workability of qualitative data collection methods. Using a blend of convenience, 200 sample participants were selected from randomly selected five Weredas of Bole sub-city.

\section{Study Area}

Addis Ababa is the capital city of Ethiopia, located in the heart of the country. The population of Addis Ababa is about three million (2011 est.) and of the total population $51.6 \%$ are female and $48.4 \%$ are male. Addis Ababa as the capital city of the country is a city where despite differences in number, almost all ethnic groups live in. The Addis Ababa City Administration comprises 10 sub-cities/zonal administrative offices and is divided into 328 dwelling associations (Qebeles) of which 305 are urban and 23 are rural. Amharic is the working language of the city administration.

Bole is one of the sub-cities/administrative zones of Addis Ababa; and it has a quite fair share of all socio-demographic features of Addis Ababa, in terms of population size, gender, ethnicity, religious affiliation, economic, and other social situation. Economic activities in Addis Ababa City include: trade and commerce; manufacturing and industry, homemaking of different variety, civil administration, transport and communication, education, health, and social services; hotel and catering services, and agriculture, animal husbandry and horticulture in the rural areas among predominant activities. According to the last six years (2002-2007) data from Addis Ababa City Administration Vital Events and Residents Services Office, total recorded marriage is 144,727 and total recorded divorce is 5,006 .

\section{Participants}

Participants of the study were those who were married couples living in the Bole sub-city of Addis Ababa City Administration. A total of 200 participants (100 female spouses and 100 male spouses), who have had more than six months married life experiences and whose age was between 20 and 59 years, from all literacy levels, religious affiliations, income levels, and other related background feature, were selected from five 
Weredas of Bole sub-city by lottery method. Literature related to marriage and divorce, reports of earlier studies, periodic report documents obtained from government offices, and educational institutions and web sites were used as secondary sources of data in this study.

\section{Study Variables}

Socio-demographic characteristics (age, gender, education, ethnicity, religion, occupation, income, duration of married life and courtship, presence of children, information about marriage) of participants that influence premarital expectations and marital satisfaction of couples. Premarital expectation and marital communication were also independent variables as predictors of marital satisfaction. Marital satisfaction was a dependent variable for all research objectives and questions, and the premarital expectation was the dependent variable for 3 rd research objective and question.

\section{Sampling Techniques and Sample Size}

Convenience and simple random sampling techniques were jointly used in this study. A convenience sampling technique is a procedure where researchers use participants that are readily available, and in numbers, they are readily available (Leary, 2001). In consultation with my advisor it determined to involve 125 couples (250 participants) out of which ultimately 100 couples (200 participants) were considered valid for final data analysis. The determined samples were subdivided into five sample Weredas of Bole sub-city, purposely equal to all selected sample Weredas so as to get data from wider residence area of the target population and increase validity and representatives of the data collected.

\section{Data Collection Instruments}

The first part of the questionnaire was about participants' socio-demographic characteristics (age, gender, education, ethnicity/nationality, religion, employment status, income, duration of married life, presence of children, source of information about marriage, and duration of courtship). The second part of the questionnaires included three sections all Likert type scale and adapted to the purpose and context of this study. The first scale was the Marital Attitude and Expectation Scale (MAES) (31 items) asking for premarital expectations (intent ( 3 items), attitudes (10 items), and general aspect of marriage (18 items)) used to measure participants anticipation on the overall aspects of marriage. The second section was Marital Communication Scale (MCS) (10 items) asking for marital communication, and the third section was Couples' Satisfaction Index (CSI with 16 items) asking for marital satisfaction of married couples. The three scales were selected from other studies done in similar fields in America, scales with already established psychometric properties.

\section{Reliability and Validity}

The questions were directly related to the subjects intended to measure. Questions related to premarital expectations (distinctively included items for measuring intent, attitude, and overall aspects of marriage), marital communication (included items focused on measuring verbal and nonverbal aspects of communication styles), and marital satisfaction (included items pertinent to measure intimacy, strength of relationship between couples, and pertinent other aspects of marital satisfaction) were worded as such. The questionnaires were translated from English into Amharic first by the researcher, and dispatched among a few fellow graduate counseling psychology students and checked by colleagues as well as by experienced counseling officers.

The pilot test was conducted before the final launching time of data collection. Twenty couples (40 spouses) were selected purposely to complete the questionnaires. The pilot test achieved its purpose and 
provided relevant information to improve the clarity and validity of the data collection tools. The data collected during the pilot test were analyzed using SPSS version 20 and checking the degree of reliability.

Table 1

Reliability Test Result of Measurement Scale

\begin{tabular}{llll}
\hline Set of scale items & Cronbach's alpha & $\begin{array}{l}\text { Cronbach's alpha based on } \\
\text { standardized items }\end{array}$ & N of items \\
\hline Premarital Expectation (MAES) & 0.616 & 0.685 & 31 \\
Marital Communication (MC) & 0.786 & 0.784 & 10 \\
Marital Satisfaction Index (MSI) & 0.954 & 0.957 & 16 \\
\hline
\end{tabular}

The acceptable Cronbach's alpha in source documents in line with the APA guide was $0.6 \leq \alpha \leq 0.7$. The pilot test result indicated that measurement scale items were reliable as presented in the above table and of course there was a need to improve quality and clarity of premarital items and also add more items required to collect data about various aspects of expectation (intent, attitudes, and general aspect of marriages). Measurement scale items used for marital communication and marital satisfaction of couples were clear and understood by respondents. Adjustment measure was taken to make these instruments easier to understand and score accordingly.

\section{Data Collection Procedures}

Data collectors were recruited and trained on fundamental issues such as understanding the purpose of the study, structure, and instructions of the questionnaires, professional ethical considerations, and working friendly with participants, so as to get participants' informed consent to deliver genuine responses to the items in the questionnaires. A guide was prepared to support the data collectors as to how they have to approach potential participants in an ethical manner. Instructions as to how to respond to all questionnaires and their rights to take part in the study and say no to whatever they do not feel like to entertain were explained to participants. If they agreed to the terms which were asked to sign a copy stating their willingness to participate in the study, then, they were asked to sign the informed consent form voluntarily. After they signed the consent form, they were given the questionnaires to be answered. Immediately after they completed answering the questionnaires, participants were informed that no detrimental effects would be expected, but if any participant feels that it has caused stress, or brought up issues that are difficult to deal with, they would be reminded of their right not to participate and share their concern.

\section{Data Analysis Procedures}

SPSS, a computer software version 20.0 was used for data analysis. The major constructs/thematic subject of the study was coded as PMEx for premarital expectations, MSat for marital satisfaction, and MCom for marital communication. All useable questionnaires were given code numbers from 001 to 200. Out of 250 copies of self-administered questionnaires distributed to potential participants only 217 copies were returned, and out of which 200 were used for final analysis. After the final checking of data validation both descriptive and inferential statistics and appropriate models were used as required and found to be appropriate to present and interpret the data in a sensible manner.

The first conducted analysis was socio-demographic data. It was performed using descriptive statistics and presented in tables including frequencies and percentage responses pertaining to categories. The second conducted analysis was quantitative data used Pearson's correlation, independent two T-test, a one-way 
ANOVA, and standard multiple linear regression models which were used as appropriate to infer results in view of seeking answers to the research question.

Accordingly, to answer the first research questions: (1) Pearson's correlation model was used to check if there was a significant relationship between couples' premarital expectations and marital satisfaction. (2) A standard multiple linear regression model was used to check if there were interrelationships between premarital expectation, marital communication, and marital satisfaction of couples. (3) ANOVA (one way) analysis of variance was used to see if there is difference in couples' premarital expectation and marital satisfaction as a function of selected socio-democratic factors such as gender, age, education level, religious affiliation, and income level, duration of courtship, and married life, and source of information about marriage. And one-sample T-test was used as an additional model to identify if there are differences in couples' premarital expectations and marital satisfaction of couples as a function of gender. Brief interpretations of results were presented immediately after the presentation of results and followed by a summary and findings of the results of the study. Significant statistical associations and mean of the difference between a dependent and independent variables were determined at alpha level $0.05(5 \%)$.

\section{Ethical Considerations}

The investigator adhered to the APA ethical considerations in terms of protection of research participant's rights and intellectual rights of authors and publishers consistently and practiced. Efforts were made and mechanisms created to obtained participants' agreement and informed consent to participate to take part in the study. Confidentiality of personal identity and privacy of participants were taken care of and ensured.

\section{Results}

\section{Analysis of Respondents' Socio-demographic Characteristics}

As socio-demographic characteristics of respondents were assumed to have a contribution to the formation of couples premarital expectations and marital satisfaction, the data obtained from respondents were analyzed and presented in the following table. Illustrated data in Table 2 age category indicate that $92(46 \%)$ of total respondents were between the age of 30-39 years, and 186 (93.0\%) of them were between 20 and 49 years old. The age ranges of respondents imply that the majority of them were from young and middle adulthood groups.

From illustrated data in Table 2, one could notice that the education level of the majority of respondents $(126,63 \%)$ were bachelor degree and above and others were at college secondary and primary schools complete level. It could also be noticed that $81(40 \%)$ of respondents earn more than 7,000 ETB and 47 (23.5\%) of them earn between 1,000-3,000 ETB. And 79 (39.5\%) of them had experience of 1-3 years courtship. From the illustrated data one could notice that sources of information about marriage for 73 (36\%) of respondents were parents. Peer groups and religious institutions were also sources of information for 108 (54\%) altogether. The result of respondents' number of children illustrated in Table 2 indicates that more than half $(108,54 \%)$ of respondents had 1-2 children. 
Table 2

Descriptive Statistics for Socio-demographic Characteristics of the Study Participants $(N=200)$

\begin{tabular}{|c|c|c|c|}
\hline Characteristics & Categories & $\mathrm{f}$ & $\%$ \\
\hline \multirow{4}{*}{ Age } & $20-29$ & 48 & 24.0 \\
\hline & $30-39$ & 92 & 46.0 \\
\hline & $40-49$ & 46 & 23.0 \\
\hline & $50-59$ & 14 & 7.0 \\
\hline \multirow{2}{*}{ Gender } & Female & 100 & 50.0 \\
\hline & Male & 100 & 50.0 \\
\hline \multirow{5}{*}{ Educational level } & Illiterate & 1 & 0.5 \\
\hline & Primary school complete & 8 & 4.0 \\
\hline & Secondary school complete & 21 & 10.5 \\
\hline & College diploma & 44 & 22.0 \\
\hline & Bachelor degree and above & 126 & 63.0 \\
\hline \multirow{4}{*}{ Duration of courtship } & Not more than one year & 63 & 31.5 \\
\hline & $1-2$ years & 49 & 24.5 \\
\hline & $2-3$ years & 30 & 15.0 \\
\hline & More than 3 years & 58 & 29.0 \\
\hline \multirow{5}{*}{ Duration of married life } & 6 months- 5 years & 89 & 44.5 \\
\hline & $6-10$ years & 58 & 29.0 \\
\hline & $11-15$ years & 31 & 15.5 \\
\hline & $16-20$ years & 9 & 4.5 \\
\hline & More than 20 years & 13 & 6.5 \\
\hline \multirow{4}{*}{ Source of information } & Parents & 73 & 36.5 \\
\hline & Religious institution & 53 & 26.5 \\
\hline & Peer group & 55 & 27.5 \\
\hline & School teachers \& others & 19 & 9.5 \\
\hline
\end{tabular}

\section{Research Question 1}

Is there any significant relationship between couples' premarital expectations, communication, and marital satisfaction? In an attempt to answer the first research question, Pearson's correlation model was conducted as it is a measure of the strength and direction of association that exists between two variables measured on at least an interval or ratio level (continuous) scale. The results have been presented in Table 3 hereunder:

Table 3

Pearson's Correlation for Premarital Expectation, Marital Communication, and Marital Satisfaction $(N=200)$

\begin{tabular}{llll}
\hline Variables & Premarital expectation & Marital communication & Marital satisfaction \\
\hline Premarital expectations & - & $0.295^{* *}$ & $0.207^{* *}$ \\
Marital communication & & & $639^{* *}$ \\
Mean & 145.22 & 39.81 & 63.84 \\
SD & 15.81 & 5.59 & 14.81 \\
\hline
\end{tabular}

Notes. ${ }^{*} \mathrm{p}<0.05 \& * * \mathrm{p}<0.01$.

As presented in Table 3, the result of a Person's correlation analysis of the relationship between and among premarital expectation, marital communication, and marital satisfaction was made clear. It was clearly indicated that respondents' average score for premarital expectation was $\mathrm{M}=145.22$ and $\mathrm{SD}=15.81$. The correlation coefficient for the relationship between premarital expectation and marital satisfaction was positive 
$(\mathrm{r}=0.207, \mathrm{p}<0.01)$, which means that when couples' premarital expectations are realistic and achievable marital satisfaction increases. Similarly, the result of correlation analysis of the relationship between marital communication and marital satisfaction $(\mathrm{M}=39.81, \mathrm{SD}=5.59$ and $\mathrm{r}=0.64, \mathrm{p}<0.05)$ indicated that there was a statistically significant positive relationship. The result of the relationship between premarital expectation and marital communication also indicated that they have a significant positive relationship $(r=0.29, p<0.05)$. Therefore, the result confirmed that there was a relationship between premarital expectation and marital satisfaction, and a strong relationship between marital communication and marital satisfaction of couples.

\section{Research Question 2}

Do couples' premarital expectations and marital communication predict the couple's marital satisfaction? Regression analysis is used when we want to predict the value of a variable based on the value of another variable. In this case, the variables we used to predict the other variable's value were the independent/predictor (premarital expectation and marital communication) variables. The variable we wished to predict (marital satisfaction) was the dependent or outcome variable. Accordingly, the standard multiple linear regression model was used to analyze the data obtained from respondents and examine whether premarital expectation and marital communication as independent variables could predict couples' marital satisfaction or not.

Table 4

Results of Standard Multiple Regression Model Conducted to Predicting Marital Satisfaction of Couples From Respondents Premarital Expectation and Marital Communication

\begin{tabular}{lllllllll}
\hline Predictors & $\mathrm{B}$ & $\beta$ & $\mathrm{t}$ & $\mathrm{P}$ & $\mathrm{R}$ & $R^{2}$ & $\mathrm{~F}$ \\
\hline \multirow{3}{*}{1} & (Constant) & -5.647 & & -0.674 & 0.50 & 0.64 & 0.41 & $68.13^{* * *}$ \\
& Premarital expectations & 0.019 & 0.020 & 0.345 & 0.73 & & & \\
& Marital communication & 1.678 & 0.633 & 11.047 & 0.001 & & & \\
\hline
\end{tabular}

Notes. a. Dependent Variable: Marital Satisfaction, $* * * \mathrm{p}<0.001$.

As it could be clearly observed in Table 4 the result reveals that predictive strength of both independent/predictor variables (premarital expectation and marital communication) accounted for $41 \%$ of variance in marital satisfaction, $\mathrm{R}^{2}=0.41, \mathrm{~F}(2,198)=68.13, \mathrm{p}<0.001$.

The premarital expectation had no significant contribution to the prediction of couples' marital satisfaction, as it could be seen after controlling marital communication, the predictive effect of premarital expectation on marital satisfaction was $b=0.02, \beta=0.02, t=0.35, p=0.73$ ). This implies that $41 \%$ of variance accounted for in marital satisfaction is only due to marital communication. On the other hand, as it could be observed in Table 4 , the contribution of marital communication on the prediction of couples' marital satisfaction, withholding premarital expectation, was significant $(b=1.68, \beta=11.1, \mathrm{t}=11.05, \mathrm{p}<0.001)$. This implies that when marital communication increased by a unit, marital satisfaction also increases by 1.68 average points.

\section{Research Question 3}

Are there socio-demographic factors contributing to changes in premarital expectations and marital satisfaction of couples? One way ANOVA was used to analyze the contribution of socio-demographic characteristics of interest to changes in premarital expectation and marital satisfaction. The result has been presented in Tables 5 and 6 for the factors influencing premarital expectation and marital satisfaction, respectively, and Table 7 presents the contribution of gender to changes in premarital expectation and marital satisfaction of couples. 
Table 5

One Way ANOVA Analysis of Variance in Changes to Premarital Expectation as a Function of Socio-demographic Characteristics

\begin{tabular}{|c|c|c|c|c|c|c|}
\hline Independent variable & $\mathrm{N}$ & M & SD & df & $\mathrm{F}$ & $\mathrm{P}$ \\
\hline \multicolumn{7}{|l|}{ Education } \\
\hline Illiterate & 2 & 133.0000 & 32.5289 & \multirow{5}{*}{$(4,195)$} & \multirow{5}{*}{2.936} & \multirow{5}{*}{0.022} \\
\hline Primary school & 9 & 132.5600 & 32.5427 & & & \\
\hline Secondary school & 20 & 139.5000 & 14.7772 & & & \\
\hline College diploma & 43 & 145.8100 & 15.7348 & & & \\
\hline BA degree and above & 126 & 147.0300 & 13.5144 & & & \\
\hline \multicolumn{7}{|l|}{ Religion } \\
\hline Orthodox & 133 & 143.8300 & 14.3960 & \multirow{4}{*}{$(3,196)$} & \multirow{4}{*}{4.264} & \multirow{4}{*}{$0.006^{*}$} \\
\hline Muslim & 5 & 153,2000 & 10.9864 & & & \\
\hline Protestant & 53 & 149.9800 & 14.0760 & & & \\
\hline Others & 9 & 133.3300 & 32.8086 & & & \\
\hline \multicolumn{7}{|l|}{ Source of information } \\
\hline Parents & 73 & 147.3600 & 12.7839 & \multirow{5}{*}{$(4,195)$} & \multirow{5}{*}{3.679} & \multirow{5}{*}{$0.007 *$} \\
\hline Religious institution & 53 & 148.6200 & 12.9282 & & & \\
\hline Peer groups & 55 & 142.8400 & 16.8861 & & & \\
\hline School teacher & 2 & 138.5000 & 12.0208 & & & \\
\hline Others & 17 & 134.0000 & 25.3056 & & & \\
\hline
\end{tabular}

Note. ${ }^{*} \mathrm{p}<0.05$.

As it could be clearly observed from Table 5, socio-demographic characteristics which were assumed to have contributed to changes in premarital expectations were, $(1)$ education $(\mathrm{F}=2.936, \mathrm{p}<0.05)$. Post hoc tests of pair-wise mean differences using Turkey's LSD also indicated that couples who were completed college diploma and university degree level had lesser expectation than couples who only completed secondary and primary schools, $(2)$ religion $(\mathrm{F}=4.264, \mathrm{p}<0.05)$. Post hoc test result did not reveal for ethical reason, and (3) source of information about marriage $(\mathrm{F}=3.679, \mathrm{p}<0.05)$. Post hoc tests of pair-wise mean differences using Turkey's statistic also indicated that couples who received marital information from parents $(13.36, p=0.013)$ and from religious institutions $(14.6, \mathrm{p}=0.00)$ have a significant contribution to changes in premarital expectation than couples who received from other sources of information.

As it could be observed from Table 6, among socio-demographic factors that were assumed to have a contribution to differences in marital satisfaction, the following factors were identified to have accounted for differences in marital satisfaction of couples. (1) Age categories $(F=5.292, p<0.05)$. Post hoc tests of pair-wise mean differences using Turkey's statistic also indicated that there were significant differences in marital satisfaction between age groups; couples who were within age bracket of 20-29 had much more marital satisfaction score than those who were in the age bracket of 50-59 with a mean difference $(17, p=0.001)$. (2) Religious affiliation $(F=2.631, p<0.05)$. Post hoc test result was not revealed for ethical reason. (3) Income level $(\mathrm{F}=3.107, \mathrm{p}<0.05)$. Post hoc tests of pairwise mean differences using Turkey's statistic also indicated significant difference in marital satisfaction between couples according to their income; participants whose income level was within income bracket of 1,000-3,000 ETB (8.6, p = 0.013) had much more marital satisfaction score than those who were in more than 7,000 ETB income category. (4) Duration of courtship (F= 3.786, $\mathrm{p}<0.05$ ). Post hoc tests of pair-wise mean differences using Turkey's statistic also indicated that 
couples within the category of 2-3 years and more than 3 years duration $(8.35, \mathrm{p}=0.05$, and $7.80, \mathrm{p}=0.018)$ had much more marital satisfaction score than those who were in the category of not more than the 1-year duration of courtship experiences.

Table 6

One Way ANOVA Analysis of Variance in Marital Satisfaction as a Function of Socio-demographic Characteristics $(N=200)$

\begin{tabular}{|c|c|c|c|c|c|c|}
\hline Independent variables & $\mathrm{N}$ & $\mathrm{M}$ & SD & $\mathrm{df}$ & $\mathrm{F}$ & $\mathrm{P}$ \\
\hline \multicolumn{7}{|l|}{ Age-years } \\
\hline $20-29$ & 48 & 66.5208 & 12.9270 & \multirow{4}{*}{$(3,196)$} & \multirow{4}{*}{5.29} & \multirow{4}{*}{0.002} \\
\hline $30-39$ & 92 & 64.5543 & 13.3444 & & & \\
\hline $40-49$ & 46 & 63.9783 & 13,1293 & & & \\
\hline $50-59$ & 14 & 49.5000 & 23.6867 & & & \\
\hline \multicolumn{7}{|l|}{ Religion } \\
\hline Orthodox & 133 & 62.4662 & 15.6214 & \multirow{4}{*}{$(3,196)$} & \multirow{4}{*}{3.63} & \multirow{4}{*}{0.014} \\
\hline Muslim & 5 & 53.4000 & 6.6558 & & & \\
\hline Protestant & 53 & 68.9245 & 11.8725 & & & \\
\hline Others & 9 & 60.0000 & 14.3527 & & & \\
\hline \multicolumn{7}{|l|}{ Income in ETB } \\
\hline$<1,000$ & 7 & 61.1429 & 28.3208 & \multirow{5}{*}{$(4,195)$} & \multirow{5}{*}{3.11} & \multirow{5}{*}{0.017} \\
\hline $1,000-3,000$ & 47 & 59.0638 & 15.1075 & & & \\
\hline $3,000-5,000$ & 37 & 61.0811 & 14.5399 & & & \\
\hline $5,000-7,000$ & 28 & 65.2500 & 11.8591 & & & \\
\hline$>7,000$ & 81 & 67.6173 & 13.8271 & & & \\
\hline \multicolumn{7}{|l|}{ Duration of Courtship } \\
\hline$<1$ year & 63 & 58.9206 & 15.2096 & \multirow{4}{*}{$(3,196)$} & \multirow{4}{*}{3.786} & \multirow{4}{*}{0.011} \\
\hline $1-2$ years & 49 & 64.6531 & 14.4461 & & & \\
\hline $2-3$ years & 30 & 67.2667 & 17.0171 & & & \\
\hline$>3$ years & 58 & 66.7241 & 12.2228 & & & \\
\hline
\end{tabular}

Note. $\mathrm{p}<0.05$.

Table 7

Independent T-Test Shows That the Variances Between Gender Group in Contribution to Changes in Premarital Expectation and Marital Satisfaction of Couples

\begin{tabular}{|c|c|c|c|c|c|c|c|c|}
\hline DV & IV & & $\mathrm{N}$ & $M$ & SD & $\mathrm{df}$ & $\mathrm{t}$ & $\mathrm{P}$ \\
\hline \multirow{2}{*}{ Marital satisfaction } & \multirow{2}{*}{ ت্ٍّ } & Female & 100 & 63.64 & 14.9537 & \multirow{2}{*}{198} & \multirow{2}{*}{-0.581} & \multirow{2}{*}{0.57} \\
\hline & & Male & 100 & 64.45 & 14.72054 & & & \\
\hline \multirow{2}{*}{$\begin{array}{l}\text { Premarital } \\
\text { expectation }\end{array}$} & \multirow{2}{*}{ نّ } & Female & 100 & 149.22 & 13.63914 & \multirow{2}{*}{198} & \multirow{2}{*}{0.013} & \multirow{2}{*}{0.08} \\
\hline & & Male & 100 & 147.21 & 17.78555 & & & \\
\hline
\end{tabular}

This table shows that gender was not significantly contributing to either premarital expectations or marital satisfaction of couples.

\section{Discussions}

The purpose of this study was to examine and describe the relationship between married couples' 
premarital expectations and marital satisfaction in the context of Addis Ababa Bole sub-city. The following paragraphs will relate the results of the current study to the review of related literature.

Unsurprisingly, after a review of the literature, this study found that premarital expectations of married couples have a significantly positive relationship with their marital satisfaction. This finding confirmed that expectations do have an effect on marital satisfaction. Consistent with the literature it is a positive correlation, meaning that fulfilled marital expectations lead to higher rates of marital happiness, and satisfaction (Koopman Boyden \& Abbott, 1985; Odell \& Quinn, 1998).

To understand the fact that there is a significant relationship between premarital expectation and marital satisfaction of couples, it is important to bring fact of life to our mind and evaluate the reality of couples' relationships on the ground. When there is a realistic and shared expectation with own partner, couples' relationship is strong and satisfying. But when expectations are unrealistic, not shared with own partner and kept hidden, it breeds marital relationship problems. Partners communicate based on perceived situation and not actually prevailing on their way to understand each other; and committed to fulfilling the required efforts to grow together.

On the other extreme partners with unrealistic and hidden expectations, it lacks the insight to observe the fact that his/her partner is a human with limitations; marriage requires to make effort to grow together; love is not enough to the marriage work; a partner cannot meets all needs; everything cannot be fair at all times; and perceived difference if not put on the table and sorted out in time, it can jeopardize marital relationships.

The second result of the current study indicated that marital communication strongly predicts couples' marital satisfaction. Different from earlier studies report, the result of the current study indicated that couples' premarital expectation was observed not significantly predict marital satisfaction. Therefore, it opens inlet for further in-depth research to find out if there are significant contextual variables contributing to the gap observed. It is also worth noticing that our observations of couples living together under a common roof but lonely emotionally or romantically. Couples who are often at conflict, but do not speak out the actual points of their misunderstanding, reflect relationship grievances in the absence of their own partner and lack the courage to talk about matters on their way to better communication.

Demographic characteristics of couples such as age, gender, religion, income, education, duration of courtship, and married life, were assumed to have a contribution to differences in couples' premarital expectations and marital satisfaction and tested. Consistent with reports of earlier studies, the result of the current study indicated that few of them were observed to have a statistically significant contribution to changes in couples' premarital expectation and marital satisfaction. Accordingly, couples' education level, religious affiliation, and sources of marital information were identified to have a significant contribution to changes in couples' premarital expectations.

Couples received most of their information from informal sources, especially the parent/family. This is consistent with the literature that addresses the importance of the family of origin and social supports ... in the marital relationship (Goldsmith \& Fitch, 1997; Larson \& Holman, 1994; MacGeorge, Feng, Butler, \& Budarz, 2004). Couples received information from many different sources. Because of the expanse of sources, couples receive information that it is important to look at them as couples, but part of a much larger system made up of smaller subsystems. Couples blend these systems to create a much larger system (Becvar \& Becvar, 1999). These findings provide evidence that for most of these couples, marriage is seen as a community event that is very open given a large number of people providing advice. The openness of the larger system in supporting 
these couples may help explain the high levels of marital satisfaction.

Similarly, couples' age, religious affiliation, income level, and duration of courtship were identified to have a significant contribution to changes in their marital satisfaction. Differences between reported facts in earlier studies and the current study lie in that, other socio-demographic factors such as the presence of children, duration of married life, which were assumed to have a contribution to changes in premarital expectations and marital satisfaction of couples but not confirmed by the result of the current study. Thus, it seems that further research is required to explore if there are cultural contexts causing the difference. An identified result pertaining to the contribution of the duration of courtship to differences in marital satisfaction was consistent with a review of the literature that couples who have more time together have more realistic and complementary expectations (Barelds \& Barelds-Dijkstra, 2007; Bonds-Raacke et al., 2001; Knoblock \& Donovan-Kicken, 2006).

\section{Recommendations}

To make use of the results of the reported study, and reduce risk factors threatening couples relationship and breeding couple conflict leading to unjust divorce, the following recommendations have been forwarded seeking the attention of married couples and significant other stakeholders:

- It is important to examine the relationship between couples' expectations and marital satisfaction to understand the level of couples' satisfaction in their married life. The unrealistic and hidden expectation is brought forward problems causing relationship problems between couples and remains unresolved until it is shared with own partner and jointly considered as a common agenda to work on and grow together.

- The finding of the reported study has indicated that marital communication predicts the state of marital satisfaction. As effective communication would predict a successful and satisfying married life, problematic marital communication would predict dissatisfying married life. It has also been indicated in this report that there were marital communication problems (lack of openness, mistrust, and failure to discuss matters that contribute to poor marital communication) between married couples who were involved in the study. Therefore, it calls for further investigation and reflects insights into remedial interventions to reduce risk factors contributing to couples' conflict which may be looming towards breeding divorce.

- As there are brought forward elements of couples' behavior from their backgrounds such as the source of marital information, education, religious affiliation, income level, duration of courtship, and others, it is important to consider the impact of socio-demographic factors contributing to couples premarital expectations and marital satisfaction.

- Married couples and significant other stakeholders may use the finding of this study to evaluate couples relationship problems so as to reduce risks contributing to their marital communication and relationship problems.

- Finally, it is commendable that further studies be conducted by competent researchers in academic and service giving institutions to fill the information gap between findings of the reported study and findings reported earlier studies. The inconsistencies were observed in findings with regards to the contribution of some of the couples' socio-demographic factors (duration of married life, presence, and number of children) to their premarital expectations and marital satisfaction; predictive effect of premarital expectation on marital satisfaction; and marital communication problems detected by the current study call further attention of researchers. 


\section{Competing Interests}

Both authors declare that they have no competing interests.

\section{References}

Baker, Kiger, \& Riley. (1996). Gender role attitudes, gender role behavior. Retrieved from http://getd.libs.uga.edu/...

Barelds, D. P. H., \& Barelds-Dijkstra, P. (2007). Love at first sight or friends first? Ties among partner personality trait similarity, relationship onset, relationship quality, and love. Journal of Social and Personal Relationships, 24(4), 479-496. Retrieved from https://doi.org/10.1177/0265407507079235

Becvar, D. S., \& Becvar, R. J. (1999). Systems theory and family therapy: A primer (2nd ed.). Lanham, MA: University Press of America.

Bonds-Raacke, J. M, Bearden, E. S., Carriere, N. J., Anderson, E. M., \& Nicks, S. D. (2001). Engaging distortions: Are we idealizing marriage? Journal of Psychology, 135(2), 179-184.

Bradbury, T. N., Fincham, F. D., \& Beach, S. R. H. (2000). Research on the nature and determinants of marital satisfaction: A decade in review. Journal of Marriage and the Family, 62, 964-980.

Brassard, A., Shaver, P. R., \& Lussier, Y. (2007). Attachment, sexual, experiences, and sexual pressure in Romantic relationships: A dyadic approach. Personal Relationships, 14, 475-493.

Goldsmith, D. J., \& Fitch, K. (1997). The normative context of advice as social support. Human Communication Research, 23(4), 454-476.

Hendrick, S., \& Hendrick, C. (1992). Romantic love. London: Sage. ISBN: 0-8039-3670-2

Jose, O., \& Alfons, V. (2007). Do demographics affect marital satisfaction? Journal of Sex \& Marital Therapy, 33, 73-85.

Kaplan, M., \& Maddux, J. E. (2002). Goals and marital satisfaction: Perceived support for personal goals and collective efficacy for collective goals. Journal of Social and Clinical Psychology, 21, 157-164.

Knoblock, L. K., \& Donovan-Kicken, E. (2006). Perceived involvement of network members in courtships: A test of the relational turbulence model. Personal Relationships, 13, 281-302.

Koopman-Boyden, P. G., \& Abbott, M. (1985). Expectations for household task allocation and actual task allocation: A New Zealand study. Journal of Marriage and the Family, 6(1), 211-219.

Lambert, N. M., \& Dollahite, D. C. (2008). The threefold cord: Marital commitment in religious couples. Journal of Family Issues, 29, 592-614.

Larson, J. H., \& Holman, T. B. (1994). Premarital predictors of marital quality and stability. Family Relations, 43, 228-237.

Leary, M. R. (2001). Introduction to behavioral research methods (3rd ed.). Needham Heights, MA: Allyn \& Bacon.

MacGeorge, E. L., Feng, B., Butler, G. L., \& Budarz, S. K. (2004). Understanding advice in supportive interactions: Beyond the face work and message evaluation paradigm. Human Communication Research, 30(1), 42-70.

Odell, M., \& Quinn, W. H. (1998). Congruence, desire for change, and adjustment during the first year of marriage. Marriage \& Family Review, 27(1/2), 91-112.

Tadesse, D. (2013). Marital satisfaction (Master's thesis, Addis Ababa University, unpublished paper).

Weigel, D. J., Bennett, K. K., \& Ballard-Reisch, D. S. (2006). Roles and influence in marriages: Both spouses' perceptions contribute to marital commitment. Family and Consumer Sciences Research Journal, 35, 74-92. 